\title{
Vegetable and fruit consumption and risks of colon and rectal cancer in a prospective cohort study: The Netherlands Cohort Study on Diet and Cancer
}

Citation for published version (APA):

Voorrips, L. E., Goldbohm, R. A., van Poppel, G. A. F. C., Sturmans, F., Hermus, R. J. J., \& van den Brandt, P. A. (2000). Vegetable and fruit consumption and risks of colon and rectal cancer in a prospective cohort study: The Netherlands Cohort Study on Diet and Cancer. American Journal of Epidemiology, 152, 1081-1092. https://doi.org/10.1093/aje/152.11.1081

Document status and date:

Published: 01/01/2000

DOI:

10.1093/aje/152.11.1081

Document Version:

Publisher's PDF, also known as Version of record

Please check the document version of this publication:

- A submitted manuscript is the version of the article upon submission and before peer-review. There can be important differences between the submitted version and the official published version of record.

People interested in the research are advised to contact the author for the final version of the publication, or visit the DOI to the publisher's website.

- The final author version and the galley proof are versions of the publication after peer review.

- The final published version features the final layout of the paper including the volume, issue and page numbers.

Link to publication

\footnotetext{
General rights rights.

- You may freely distribute the URL identifying the publication in the public portal. please follow below link for the End User Agreement:

www.umlib.nl/taverne-license

Take down policy

If you believe that this document breaches copyright please contact us at:

repository@maastrichtuniversity.nl

providing details and we will investigate your claim.
}

Copyright and moral rights for the publications made accessible in the public portal are retained by the authors and/or other copyright owners and it is a condition of accessing publications that users recognise and abide by the legal requirements associated with these

- Users may download and print one copy of any publication from the public portal for the purpose of private study or research.

- You may not further distribute the material or use it for any profit-making activity or commercial gain

If the publication is distributed under the terms of Article $25 \mathrm{fa}$ of the Dutch Copyright Act, indicated by the "Taverne" license above, 


\title{
Vegetable and Fruit Consumption and Risks of Colon and Rectal Cancer in a Prospective Cohort Study
}

\author{
The Netherlands Cohort Study on Diet and Cancer
}

\author{
L. E. Voorrips, ${ }^{1}$ R. A. Goldbohm, ${ }^{1}$ G. van Poppel, ${ }^{1}$ F. Sturmans, ${ }^{2}$ R. J. J. Hermus, ${ }^{1}$ and P. A. van den Brandt ${ }^{2}$
}

\begin{abstract}
The relation between vegetable and fruit consumption and colorectal cancer risk was comprehensively assessed in the Netherlands Cohort Study on Diet and Cancer using a validated 150-item food frequency questionnaire. After 6.3 years of follow-up (1986-1992), over 1,000 incident cases of colorectal cancer were registered. Using case-cohort analysis, the authors calculated rate ratios and $95 \%$ confidence intervals adjusted for age, alcohol intake, and family history of colorectal cancer. For colon cancer, no statistically significant associations with total vegetable intake or total fruit intake were found. However, among women, an inverse association was observed with vegetables and fruits combined (for the highest quintile vs. the lowest, the rate ratio was 0.66 (95\% confidence interval: $0.44,1.01)$ ). Brassica vegetables and cooked leafy vegetables showed inverse associations for both men and women. Among women and, to a lesser extent, among men, inverse associations were stronger for distal colonic tumors than for proximal colonic tumors. For rectal cancer, no statistically significant associations were found for vegetable consumption or fruit consumption or for specific groups of vegetables and fruits; only Brassica vegetables showed a positive association in women. As in other cohort studies, the observed inverse relation between vegetable and fruit consumption and occurrence of colorectal cancer was less strong than relations reported in case-control studies. Am J Epidemiol 2000;152:1081-92.
\end{abstract}

cohort studies; colonic neoplasms; dietary fiber; fruit; rectal neoplasms; vegetables

Several investigators have summarized epidemiologic data considering the effect of vegetable and fruit consumption on cancer risk (1-4). In the most recent review by Steinmetz and Potter (4), 15 of the 21 case-control studies examined showed statistically significant inverse associations between one or more vegetable/fruit categories and colon cancer risk. Four of the studies did not show significant inverse associations for any vegetable/fruit category, and in two studies statistical significance was not reported. The protective effect of vegetables seemed to be most clear for raw vegetables and the green types. The case-control evidence did not support a protective effect of legumes against colon cancer. For cancer of the rectum, eight out of 13 studies showed significant inverse associations; two did not show associations, and in three studies, significance was not reported. The evidence of a protective effect on rectal cancer was most consistent for cruciferous vegetables.

To date, data from 11 prospective cohort studies on vegetable/fruit consumption (or on fiber from vegetables/fruits)

Received for publication August 18, 1998, and accepted for publication February 4, 2000.

Abbreviations: $\mathrm{Cl}$, confidence interval; $\mathrm{RR}$, rate ratio.

${ }^{1}$ Department of Nutritional Epidemiology, TNO Nutrition and Food Research, Zeist, The Netherlands.

${ }^{2}$ Department of Epidemiology, Maastricht University, Maastricht, The Netherlands.

Correspondence to Dr. Laura E. Voorrips, Department of Nutritional Epidemiology, TNO Nutrition and Food Research, P.O. Box 360, 3700 AJ Zeist, The Netherlands (e-mail: Voorrips@voeding.tno.nl). and risk of (fatal) colon or rectal cancer or colorectal adenoma have been published. Two studies examined SeventhDay Adventists $(5,6)$, one examined Japanese-American men residing in Hawaii (7), and one examined vegetarians and health-conscious people (8). Furthermore, data have been published from the Nurses' Health Study $(9,10)$, the Second Cancer Prevention Study (11), the Leisure World Study (12), the Iowa Women's Health Study (13), the Health Professionals Follow-up Study (14-16), the New York University Women's Health Study (17), and the AlphaTocopherol, Beta-Carotene Cancer Prevention Study (18). Only statistically nonsignificant inverse associations between vegetable or fruit consumption and colorectal cancer risk have been found. With two exceptions $(8,18)$, all data from cohort studies that have been published so far have come from the United States. Only three studies published data on both men and women, in separate analyses (5, $11,12)$. Most studies focused on colon cancer or colorectal cancer, not allowing for separate conclusions regarding rectal cancer. Four studies presented data on more than one vegetable item $(6,12,13,18)$.

With 6.3 years of follow-up, the Netherlands Cohort Study on Diet and Cancer has accrued over 1,000 colorectal cancer cases. This large number has enabled us to study the relation between intake of vegetables and fruits (including subgroup analyses) and colorectal cancer risk in both men and women with a Western European diet. We were able to perform separate analyses for colon and rectal cancer and for specific subsites in the colon. Because the association 
between consumption of Allium vegetables and colorectal carcinoma risk has already been examined in the Netherlands Cohort Study (19), specific analyses for these vegetables were not included in the present paper.

\section{MATERIALS AND METHODS}

\section{The Netherlands Cohort Study}

The Netherlands Cohort Study on Diet and Cancer is a prospective cohort study that was started in September 1986. The study design has been reported in detail elsewhere (20). In brief, the cohort included 62,573 women and 58,279 men aged 55-69 years at the beginning of the study who originated from 204 Dutch municipalities with computerized population registries. A self-administered mailed questionnaire on dietary habits, lifestyle, smoking, personal and family history of cancer, and demographic data was completed at baseline. Accumulation of person-time in the cohort has been estimated through biennial vital status follow-up of a subcohort of 1,688 men and 1,812 women who were randomly selected after baseline exposure measurement. No subcohort members were lost to follow-up.

\section{Identification of cases of colon and rectal cancer}

The method of record linkage used to obtain information on cancer incidence has been described previously (21). In short, follow-up for incident cancer has been established by computerized record linkage of the entire cohort with all regional cancer registries in the Netherlands and with PALGA, a national database of pathology reports. For prevention of random and systematic coding errors, the questionnaire data of all cases and subcohort members have been key-entered twice and processed blinded with respect to case/subcohort status.

\section{The food frequency questionnaire}

The dietary section of the questionnaire was a 150 -item semiquantitative food frequency questionnaire. The questionnaire concentrated on habitual consumption of food and beverages during the year preceding the start of the study. With regard to vegetable consumption, participants were asked to report their frequency of consumption of 15 cooked vegetables and four raw vegetables, both in summer and in winter. For most vegetables, the questionnaire explicitly specified whether the vegetable was eaten raw or cooked. On the basis of results from the Dutch Nutrition Survey (22), onions and sweet peppers were considered to be eaten cooked, while tomatoes were considered to be eaten raw. Participants could indicate their frequency of consumption by choosing one of six categories ranging from "never or less than once per month" to "three to seven times per week."

Participants were asked about usual serving sizes only for string beans and cooked endive; the mean of these values served as an indicator for the serving sizes of all cooked vegetables. Subjects who did not report their usual serving sizes were assigned a default value. For subjects with only one reported serving size, the individual serving size was derived using a conversion factor. Both the default value and the conversion factor were derived from a pilot study. For tomatoes and sweet peppers, participants were asked to report their consumption in number of pieces per week and per month, respectively, for both summer and winter.

With regard to fruit consumption, participants were asked to report frequencies (varying from "never or less than once per month" to "six or seven times per week") and amounts consumed for oranges, mandarins, grapefruits, grapes, bananas; apples/pears, and strawberries. Using standard sizes, we converted these frequencies and amounts to grams per day.

An open-ended question on other food eaten regularly was also included. Participants could write down how often they ate such a food per week and how much they ate on each occasion.

The food frequency questionnaire was validated against a 9-day diet record. Spearman correlation coefficients for vegetables and fruits were 0.60 and 0.38 , respectively. Vegetable consumption appeared to be slightly overestimated and fruit consumption to be underestimated by the food frequency questionnaire as compared with the diet records (23).

\section{Study population}

After exclusion of 1) cases who reported prevalent cancer at baseline (other than nonmelanoma skin cancer), 2) cases without microscopically confirmed cancer, 3) cases with incident carcinoma in situ, and 4) cases with colon and rectal cancers other than carcinoma (sarcoma, lymphoma, cancers of unspecified morphology), 659 incident colon carcinoma cases and 375 rectal carcinoma cases were available for analyses, using the first 6.3 years of follow-up. Cases with prevalent cancer other than nonmelanoma skin cancer were excluded from the subcohort as well, which left 1,716 women and 1,630 men for analysis. Furthermore, subjects with incomplete or inconsistent dietary data were excluded from the analyses. These subjects included 1) those who left 60 or more (out of 150) questionnaire items blank and ate fewer than 35 items at least once per month and 2) those who left one or more item blocks (groups of items, e.g., beverages) blank. Additional details are given elsewhere (23).

Questions on vegetable consumption appeared early in the food frequency questionnaire. This led to some subjects' making mistakes on these particular items (e.g., improbably high summed frequencies for vegetable consumption, errors in separate consumption frequencies for summer and winter, and improbably high (or low) reported portion sizes), while items on other food groups appearing further along in the questionnaire were filled out without problems. In order to check the quality of the responses to the vegetable questions, we computed a vegetable error index. When the vegetable error index exceeded a certain value, i.e., more than three errors, that subject was excluded from the analyses of vegetable consumption. For vegetable consumption, the final analysis was based on a total of 587 colon cancer cases 
( 313 men and 274 women), 323 rectal cancer cases (201 men and 122 women), and 2,953 subcohort members (1,456 men and 1,497 women). For fruit consumption, the final analysis was based on 620 colon cancer cases ( 332 men and 288 women), 344 rectal cancer cases ( 217 men and 127 women), and 3,123 subcohort members (1,525 men and 1,598 women).

\section{Data analysis}

Analyses were performed for total vegetable consumption, total fruit consumption, consumption of vegetables and fruits combined, consumption of individual vegetables and fruits as listed in the questionnaire, and consumption of vegetable/fruit groups (raw vegetables, cooked vegetables, legumes, Brassica vegetables, cooked and raw leafy vegetables, and citrus fruit). "Total vegetable consumption" is the summed total for all vegetables mentioned in the questionnaire and in the open-ended question. Although results on Allium vegetables are not reported separately, they were included in total vegetable consumption. For analysis of vegetable consumption, potatoes and mature beans were not included.

Subjects were classified into quintiles, tertiles, or categories of vegetable or fruit consumption (g/day), depending on the data distribution in the subcohort. Analyses were performed using the case-cohort approach (24). In this approach, cases are enumerated for the entire cohort, while person-years at risk for the cohort are estimated using the subcohort sample.

We computed age-adjusted rate ratios for colon and rectal cancer (and their 95 percent confidence intervals) using the GLIM statistical package (25). Exponentially distributed survival times were assumed in the follow-up period. Since standard software was not available for case-cohort analysis, we developed specific macros to account for the additional variance introduced by sampling from the cohort instead of using the entire cohort (26). Tests for trends in rate ratios were based on two-sided likelihood ratio tests. Total energy consumption, alcohol intake, smoking, physical activity, body mass index (reported weight $(\mathrm{kg})$ divided by reported height (m) squared), and family history of colorectal cancer were evaluated as potential confounders. In our study, family history of colorectal cancer and alcohol intake were related to colorectal cancer, and we adjusted for these factors in a multivariate model. Rate ratios for the mean daily quantities of specific vegetables and fruits consumed were calculated for continuous variables ( $g /$ day) and are expressed in increments of $25 \mathrm{~g} /$ day. This increment corresponds to a consumption frequency of approximately once per week for a cooked vegetable. The independent contribution of each specific vegetable was assessed through analyses in which all other vegetables or fruits were included in the model simultaneously.

Separate analyses were conducted for colon and rectal carcinoma in males and females. For colon cancer, subgroup analyses were performed for proximal and distal colon carcinomas. Analyses were repeated after exclusion of cases diagnosed during the first 2 years of follow-up.

\section{RESULTS}

Table 1 presents mean vegetable and fruit consumption, by sex, for cases with incident colon and rectal cancer and for members of the subcohort. Mean daily fruit consumption among subcohort members was more than $40 \mathrm{~g}$ higher for women than for men, whereas differences in vegetable consumption were less striking. Consumption of vegetables by male colon and rectal cancer cases was not different from that of subcohort members, whereas fruit consumption was slightly higher among male colon cancer cases than in the subcohort. For women, both vegetable consumption and fruit consumption were lower among colon cancer cases than among subcohort members. For female rectal cancer cases, vegetable consumption was higher and fruit consumption was lower than that of subcohort members.

For subcohort members, vegetable and fruit consumption was calculated for strata of the most important potential confounders: alcohol intake and family history of colorectal cancer (table 2). Vegetable consumption was calculated for subcohort members in different quintiles of fruit consumption, and fruit consumption was calculated for subcohort members in different quintiles of vegetable consumption. Fruit consumption was higher in the higher age groups for both men and women. For vegetable consumption, no age effect was found. Vegetable consumption was higher with increasing alcohol intake in men, and this trend was even stronger in women. For fruit consumption, no association with alcohol intake was found. Small differences in vegetable and fruit consumption were found between people with and without a family history of colorectal cancer. In both men and women, higher fruit consumption was associated with higher vegetable consumption.

Tables 3 and 4 present rate ratios for colon and rectal cancer, respectively, according to quintiles of vegetable consumption, fruit consumption, and the combination of vegetable and fruit consumption. Rate ratios were adjusted both for age only and for age, family history of colorectal cancer, and alcohol intake. In women, nonsignificant inverse associations with colon cancer were found for fruit consumption and consumption of vegetables/fruits combined. However, a nonsignificant positive association with rectal cancer was found for vegetable consumption in women. Among men, no inverse associations were found for colon or rectal cancer, and fruit consumption even showed a slight positive trend for colon cancer.

Vegetables and fruits were divided into groups, and rate ratios were calculated for quintiles of consumption using the multivariate model (table 5). For colon cancer in men, negative associations were seen for Brassica vegetables (rate ratio (RR) for the highest quintile vs. the lowest (hereafter called high/low RR) $=0.76$ (95 percent confidence interval (CI): $0.51,1.13), p$ trend $=0.11$ ) and for cooked leafy vegetables (high/low $\mathrm{RR}=0.75$ (95 percent CI: $0.50,1.13$ ), $p$ trend $=0.05$ ). In women, Brassica vegetables and cooked leafy vegetables also showed the strongest negative associations with colon cancer (high/low RR $=0.51$ (95 percent CI: $0.33,0.80), p$ trend $=0.004$, and high/low $\mathrm{RR}=$ 0.62 (95 percent CI: $0.40,0.96), p$ trend $=0.06$, respectively). With regard to rectal cancer, no associations with 


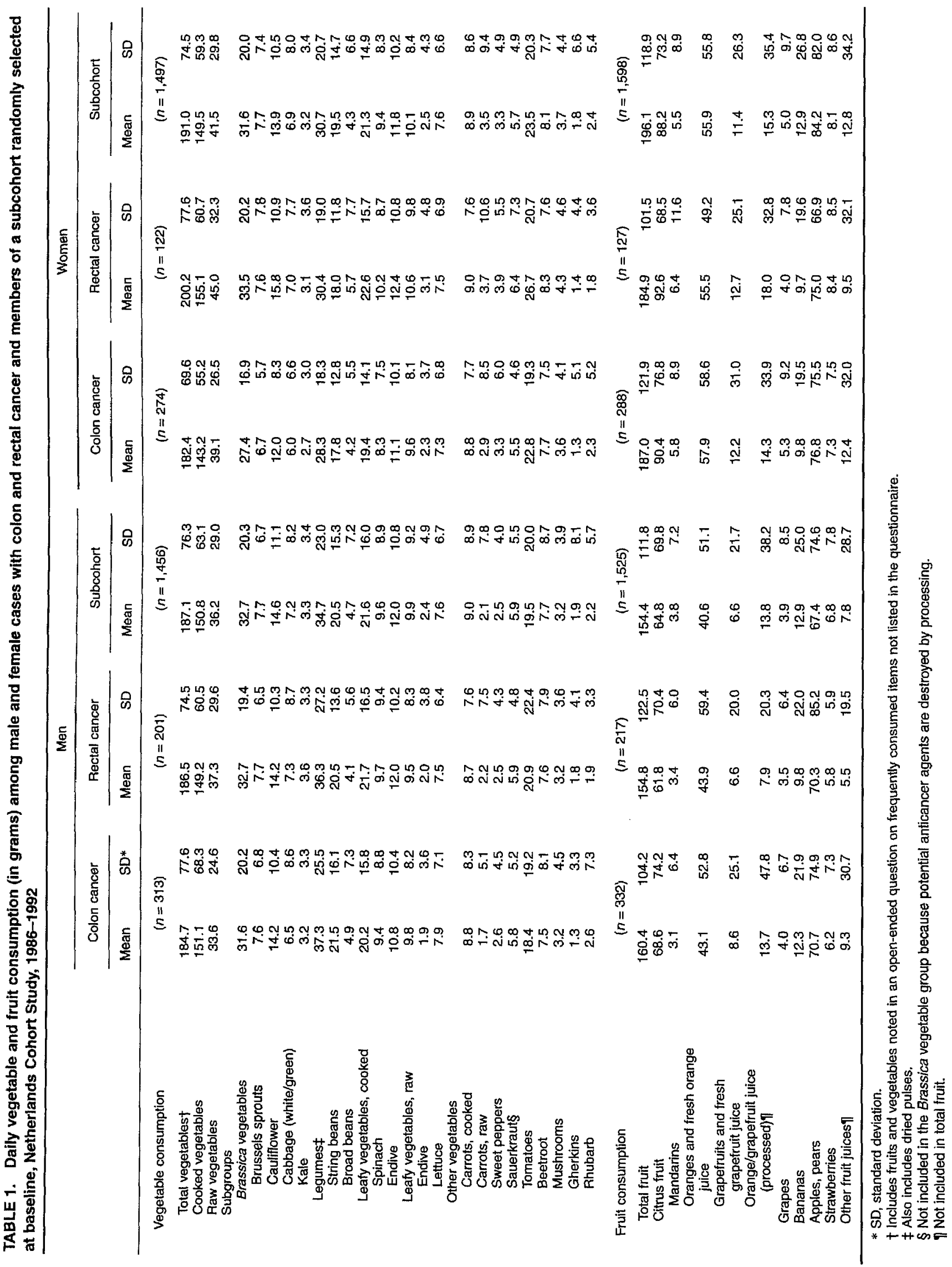


TABLE 2. Mean daily consumption of vegetables and fruits in a subcohort randomly selected at baseline, according to several characteristics, Netherlands Cohort Study, 1986-1992

\begin{tabular}{|c|c|c|c|c|c|c|c|c|c|c|c|c|}
\hline \multirow{3}{*}{ Characteristic } & \multicolumn{6}{|c|}{ Vegetable consumption* } & \multicolumn{6}{|c|}{ Fruit consumption* } \\
\hline & \multicolumn{3}{|c|}{$\begin{array}{c}\text { Men } \\
(n=1,456)\end{array}$} & \multicolumn{3}{|c|}{$\begin{array}{c}\text { Women } \\
(n=1,497)\end{array}$} & \multicolumn{3}{|c|}{$\begin{array}{c}\text { Men } \\
(n=1,525)\end{array}$} & \multicolumn{3}{|c|}{$\begin{array}{c}\text { Women } \\
(n=1,598)\end{array}$} \\
\hline & No. & $\begin{array}{c}\text { Mean } \\
\text { (g/day) }\end{array}$ & SDt & No. & $\begin{array}{c}\text { Mean } \\
\text { (g/day) }\end{array}$ & SD & No. & $\begin{array}{c}\text { Mean } \\
\text { (g/day) }\end{array}$ & SD & No. & $\begin{array}{c}\text { Mean } \\
\text { (g/day) }\end{array}$ & SD \\
\hline \multicolumn{13}{|l|}{ Age (years) } \\
\hline $55-59$ & 562 & 185 & 78 & 570 & 192 & 75 & 582 & 148 & 109 & 616 & 192 & 125 \\
\hline $60-64$ & 505 & 189 & 75 & 520 & 194 & 74 & 534 & 154 & 111 & 548 & 198 & 114 \\
\hline $65-69$ & 389 & 187 & 76 & 407 & 186 & 74 & 409 & 165 & 116 & 434 & 199 & 116 \\
\hline \multicolumn{13}{|c|}{ Alcohol intake (g/day) $\ddagger$} \\
\hline 0 & 219 & 176 & 87 & 457 & 184 & 77 & 231 & 158 & 106 & 488 & 199 & 124 \\
\hline $0.1-4$ & 290 & 185 & 75 & 526 & 190 & 72 & 304 & 173 & 132 & 563 & 195 & 114 \\
\hline $5-14$ & 405 & 180 & 69 & 263 & 198 & 73 & 422 & 156 & 103 & 278 & 196 & 114 \\
\hline $15-29$ & 327 & 193 & 69 & 131 & 203 & 77 & 341 & 144 & 102 & 137 & 181 & 120 \\
\hline$\geq 30$ & 202 & 205 & 88 & 50 & 219 & 73 & 210 & 141 & 117 & 53 & 198 & 112 \\
\hline \multicolumn{13}{|c|}{$\begin{array}{l}\text { Family history of colorectal } \\
\text { cancer }\end{array}$} \\
\hline No & 1,377 & 187 & 77 & 1,415 & 191 & 74 & 1,441 & 154 & 112 & 1,511 & 196 & 120 \\
\hline Yes & 79 & 184 & 67 & 82 & 193 & 82 & 84 & 155 & 113 & 87 & 191 & 99 \\
\hline \multicolumn{13}{|c|}{$\begin{array}{l}\text { Quintile of vegetable/fruit } \\
\text { consumption } \S\end{array}$} \\
\hline 1 (low) & 293 & 165 & 70 & 214 & 166 & 69 & 299 & 128 & 100 & 314 & 158 & 113 \\
\hline 2 & 287 & 184 & 75 & 288 & 180 & 72 & 303 & 140 & 103 & 302 & 188 & 106 \\
\hline 3 & 296 & 182 & 69 & 303 & 189 & 73 & 298 & 150 & 103 & 319 & 187 & 107 \\
\hline 4 & 292 & 194 & 73 & 325 & 199 & 69 & 300 & 159 & 103 & 304 & 204 & 112 \\
\hline 5 (high) & 288 & 210 & 87 & 367 & 209 & 80 & 325 & 192 & 134 & 359 & 238 & 136 \\
\hline
\end{tabular}

* Total numbers differ for vegetable and fruit consumption because of an extra exclusion criterion for analysis of vegetable consumption.

† SD, standard deviation.

$¥$ Numbers do not total 2,953 (vegetable consumption) or 3,123 (fruit consumption) because of missing values.

$\S$ Total vegetable consumption by quintile of fruit consumption, and total fruit consumption by quintile of vegetable consumption.

consumption of particular groups of vegetables or fruits were found in men. In women, a positive association found with vegetables was strongest for vegetables in the Brassica group (high/low $\mathrm{RR}=1.66$ (95 percent CI: 0.94, 2.94), $p$ trend $=0.05$ ).

Table 6 presents rate ratios from models containing all confounders for $25-\mathrm{g} /$ day increments in consumption of specific vegetables and fruits, both with and without additional adjustment for other vegetables or other fruits. Among men, statistically significant negative associations with colon cancer were found for cooked endive in both models; among women, significant negative associations were found for cauliflower and spinach in the model that included adjustment for other cooked vegetables. In the model that did not include other vegetables, negative associations of brussels sprouts, cabbage, and string beans with colon cancer in women were borderline significant. With regard to rectal cancer, significant positive associations were found among women for cauliflower and broad beans in both models.

Colon cancer cases were classified according to site of occurrence (proximal vs. distal), and for each site rate ratios were calculated for total vegetable and fruit consumption, total vegetable consumption, total fruit consumption, and consumption of Brassica vegetables (the most notable vegetable group in table 6). Overall, the incidence of cancer in the distal colon seemed to be more influenced by vegetable consumption than was incidence in the proximal colon. Regarding cancer of the distal colon in women, statistically significant negative associations were found for all vegeta- bles and fruits (high/low RR $=0.44$ (95 percent CI: 0.23 , 0.82 ), $p$ trend $=0.01$ ), for total vegetables (high/low $R R=$ 0.64 (95 percent CI: $0.36,1.17$ ), $p$ trend $=0.04$ ), and for Brassica vegetables (high/low $\mathrm{RR}=0.47$ (95 percent $\mathrm{CI}$ : $0.25,0.89$ ), $p$ trend $=0.02$ ) (table 7). In men, only Brassica vegetables showed a statistically significant negative association with distal colon cancer (high/low $R R=0.68$ (95 percent CI: $0.41,1.15$ ), $p$ trend $=0.02$ ). When the analyses of total vegetable consumption and total vegetable/fruit consumption were repeated with Brassica vegetables included in the model, the inverse association with total vegetable consumption was lost but the inverse relation between total vegetable/fruit consumption and cancer of the distal colon was maintained for women (results not shown). Rate ratios for increasing quintiles of total vegetable/fruit intake were $1.0,0.66,0.77,0.65$, and 0.53 , respectively. Therefore, for women, negative associations with vegetable consumption could be interpreted as being mainly due to consumption of Brassica vegetables.

\section{DISCUSSION}

After 6.3 years of follow-up in the Netherlands Cohort Study on Diet and Cancer, some evidence was found for an inverse association between consumption of vegetables and/or fruit in general and the incidence of colon (but not rectal) cancer. As was noted above, case-control studies tend to report clearly negative associations between vegetable and fruit consumption and colon or rectal cancer, but evi- 
TABLE 3. Rate ratios for colon cancer according to quintiles of vegetable and/or fruit consumption in men and women, Netherlands Cohort Study, 1986-1992

\begin{tabular}{|c|c|c|c|c|c|c|c|}
\hline \multirow{2}{*}{$\begin{array}{c}\text { Quintile } \\
\text { of } \\
\text { consumption }\end{array}$} & \multirow{2}{*}{$\begin{array}{l}\text { Median } \\
\text { intake } \\
\text { (g/day) }\end{array}$} & \multirow{2}{*}{$\begin{array}{l}\text { No. } \\
\text { of } \\
\text { cases }\end{array}$} & \multirow{2}{*}{$\begin{array}{c}\text { Person- } \\
\text { years } \\
\text { of } \\
\text { observation }\end{array}$} & \multicolumn{2}{|c|}{$\begin{array}{l}\text { Age-adjusted } \\
\text { rate ratio }\end{array}$} & \multicolumn{2}{|c|}{$\begin{array}{l}\text { Multiply adjusted } \\
\text { rate ratio* }\end{array}$} \\
\hline & & & & RRT & $95 \% \mathrm{Cl}$ & $R R$ & $95 \% \mathrm{Cl}$ \\
\hline \multicolumn{8}{|l|}{ Men } \\
\hline \multicolumn{8}{|c|}{ Total vegetables and fruits } \\
\hline 1 (low) $\ddagger$ & 177 & 62 & 1,739 & 1.00 & & 1.00 & \\
\hline 2 & 257 & 55 & 1,694 & 0.86 & $0.57,1.29$ & 0.85 & $0.57,1.28$ \\
\hline 3 & 319 & 66 & 1,777 & 1.01 & $0.69,1.49$ & 1.00 & $0.67,1.47$ \\
\hline 4 & 393 & 65 & 1,715 & 1.00 & $0.68,1.48$ & 1.00 & $0.68,1.48$ \\
\hline 5 (high) & 519 & 64 & 1,748 & 0.96 & $0.65,1.43$ & 0.95 & $0.64,1.41$ \\
\hline$p$-trend & & & & 0.85 & & 0.90 & \\
\hline \multicolumn{8}{|l|}{ Total vegetables } \\
\hline 1 (low) $\ddagger$ & 100 & 65 & 1,713 & 1.00 & & 1.00 & \\
\hline 2 & 144 & 64 & 1,765 & 0.96 & $0.65,1.41$ & 0.96 & $0.65,1.42$ \\
\hline 3 & 175 & 61 & 1,745 & 0.94 & $0.64,1.39$ & 0.92 & $0.62,1.36$ \\
\hline 4 & 214 & 65 & 1,761 & 1.00 & $0.68,1.47$ & 0.98 & $0.66,1.44$ \\
\hline 5 (high) & 285 & 57 & 1,689 & 0.89 & $0.60,1.32$ & 0.85 & $0.57,1.27$ \\
\hline$p$-trend & & & & 0.65 & & 0.45 & \\
\hline \multicolumn{8}{|l|}{ Total fruit } \\
\hline $1($ low $) \ddagger$ & 34 & 56 & 1,817 & 1.00 & & 1.00 & \\
\hline 2 & 91 & 75 & 1,765 & 1.41 & $0.96,2.07$ & 1.40 & $0.95,2.06$ \\
\hline 3 & 136 & 50 & 1,811 & 0.90 & $0.59,1.36$ & 0.91 & $0.60,1.38$ \\
\hline 4 & 187 & 74 & 1,823 & 1.25 & $0.85,1.84$ & 1.29 & $0.87,1.90$ \\
\hline 5 (high) & 286 & 76 & 1,840 & 1.31 & $0.89,1.93$ & 1.33 & $0.90,1.97$ \\
\hline$p$-trend & & & & 0.28 & & 0.22 & \\
\hline \multicolumn{8}{|l|}{ Women } \\
\hline \multicolumn{8}{|c|}{ Total vegetables and fruits } \\
\hline $1(\mathrm{low}) \ddagger$ & 208 & 71 & 1,794 & 1.00 & & 1.00 & \\
\hline 2 & 298 & 42 & 1,714 & 0.62 & $0.41,0.94$ & 0.63 & $0.41,0.97$ \\
\hline 3 & 370 & 54 & 1,765 & 0.77 & $0.52,1.14$ & 0.77 & $0.52,1.15$ \\
\hline 4 & 444 & 54 & 1,770 & 0.76 & $0.52,1.12$ & 0.77 & $0.51,1.14$ \\
\hline 5 (high) & 578 & 45 & 1,762 & 0.65 & $0.43,0.97$ & 0.66 & $0.44,1.01$ \\
\hline$p$-trend & & & & 0.08 & & 0.10 & \\
\hline \multicolumn{8}{|l|}{ Total vegetables } \\
\hline 1 (low) $\ddagger$ & 107 & 64 & 1,775 & 1.00 & & 1.00 & \\
\hline 2 & 147 & 48 & 1,701 & 0.80 & $0.53,1.20$ & 0.83 & $0.54,1.26$ \\
\hline 3 & 181 & 59 & 1,837 & 0.92 & $0.63,1.36$ & 0.95 & $0.64,1.42$ \\
\hline 4 & 220 & 47 & 1,759 & 0.78 & $0.52,1.17$ & 0.79 & $0.52,1.20$ \\
\hline 5 (high) & 293 & 48 & 1,733 & 0.80 & $0.53,1.20$ & 0.83 & $0.54,1.26$ \\
\hline$p$-trend & & & & 0,25 & & 0.31 & \\
\hline \multicolumn{8}{|l|}{ Total fruit } \\
\hline 1 (low) $\ddagger$ & 65 & 45 & 1,324 & 1.00 & & 1.00 & \\
\hline 2 & 124 & 59 & 1,779 & 0.96 & $0.63,1.46$ & 0.95 & $0.62,1.45$ \\
\hline 3 & 177 & 49 & 1,821 & 0.79 & $0.51,1.23$ & 0.78 & $0.50,1.22$ \\
\hline 4 & 237 & 66 & 2,028 & 0.91 & $0.60,1.38$ & 0.91 & $0.60,1.38$ \\
\hline 5 (high) & 343 & 61 & 2,404 & 0.72 & $0.48,1.10$ & 0.73 & $0.48,1.11$ \\
\hline$p$-trend & & & & 0.10 & & 0.12 & \\
\hline
\end{tabular}

* Adjusted for age, family history of colorectal cancer, and category of alcohol intake.

$\dagger \mathrm{RA}$, rate ratio; $\mathrm{Cl}$, confidence interval.

¥ Reference category.

dence from cohort studies that has been published thus far is less strong.

In review articles, studies showing at least one significant inverse association are generally treated as being supportive of the hypothesis that vegetables and fruits protect against colorectal cancer. Thus, studies with a negative association for one vegetable/fruit group but positive associations for other vegetable/fruit groups will often be categorized as presenting negative associations. Although this may bias conclusions about the strength of the protective effect of veg- 
TABLE 4. Rate ratios for rectal cancer according to quintiles of vegetable and/or fruit consumption in men and women, Netherlands Cohort Study, 1986-1992

\begin{tabular}{|c|c|c|c|c|c|c|c|}
\hline \multirow{2}{*}{$\begin{array}{c}\text { Quintile } \\
\text { of } \\
\text { consumption }\end{array}$} & \multirow{2}{*}{$\begin{array}{l}\text { Median } \\
\text { intake } \\
\text { (g/day) }\end{array}$} & \multirow{2}{*}{$\begin{array}{l}\text { No. } \\
\text { of } \\
\text { cases }\end{array}$} & \multirow{2}{*}{$\begin{array}{l}\text { Person- } \\
\text { years } \\
\text { of } \\
\text { observation }\end{array}$} & \multicolumn{2}{|c|}{$\begin{array}{l}\text { Age-adjusted } \\
\text { rate ratio }\end{array}$} & \multicolumn{2}{|c|}{$\begin{array}{l}\text { Multiply adjusted } \\
\text { rate ratio* }\end{array}$} \\
\hline & & & & RRt & $95 \% \mathrm{Clt}$ & $\mathrm{RR}$ & $95 \% \mathrm{Cl}$ \\
\hline \multicolumn{8}{|l|}{ Men } \\
\hline \multicolumn{8}{|c|}{ Total vegetables and fruits } \\
\hline 1 (low) $\ddagger$ & 177 & 47 & 1,743 & 1.00 & & 1.00 & \\
\hline 2 & 257 & 34 & 1,694 & 0.72 & $0.45,1.14$ & 0.72 & $0.44,1.15$ \\
\hline 3 & 319 & 31 & 1,779 & 0.63 & $0.39,1.02$ & 0.63 & $0.39,1.02$ \\
\hline 4 & 393 & 43 & 1,716 & 0.90 & $0.58,1.39$ & 0.90 & $0.57,1.41$ \\
\hline 5 (high) & 519 & 44 & 1,760 & 0.89 & $0.57,1.38$ & 0.88 & $0.56,1.37$ \\
\hline p-trend & & & & 0.94 & & 0.90 & \\
\hline \multicolumn{8}{|l|}{ Total vegetables } \\
\hline 1 (low) $\ddagger$ & 100 & 42 & 1,717 & 1.00 & & 1.00 & \\
\hline 2 & 144 & 39 & 1,765 & 0.91 & $0.57,1.44$ & 0.89 & $0.56,1.43$ \\
\hline 3 & 175 & 39 & 1,746 & 0.93 & $0.58,1.47$ & 0.88 & $0.55,1.41$ \\
\hline 4 & 214 & 39 & 1,761 & 0.92 & $0.58,1.46$ & 0.87 & $0.54,1.39$ \\
\hline 5 (high) & 285 & 40 & 1,703 & 0.96 & $0.61,1.52$ & 0.88 & $0.55,1.41$ \\
\hline$p$-trend & & & & 0.89 & & 0.58 & \\
\hline \multicolumn{8}{|l|}{ Total fruit } \\
\hline 1 (low) $\ddagger$ & 34 & 50 & 1,822 & 1.00 & & 1.00 & \\
\hline 2 & 91 & 48 & 1,771 & 1.00 & $0.65,1.52$ & 0.99 & $0.64,1.52$ \\
\hline 3 & 136 & 32 & 1,818 & 0.64 & $0.40,1.02$ & 0.65 & $0.40,1.05$ \\
\hline 4 & 187 & 42 & 1,824 & 0.81 & $0.52,1.26$ & 0.84 & $0.54,1.31$ \\
\hline 5 (high) & 286 & 43 & 1,842 & 0.84 & $0.54,1.29$ & 0.85 & $0.55,1.32$ \\
\hline$p$-trend & & & & 0.22 & & 0.29 & \\
\hline \multicolumn{8}{|l|}{ Women } \\
\hline \multicolumn{8}{|c|}{ Total vegetables and fruits } \\
\hline 1 (low) $\ddagger$ & 208 & 20 & 1,797 & 1.00 & & 1.00 & \\
\hline 2 & 298 & 24 & 1,706 & 1.26 & $0.68,2.33$ & 1.27 & $0.69,2.35$ \\
\hline 3 & 370 & 26 & 1,765 & 1.32 & $0.72,2.42$ & 1.33 & $0.73,2.43$ \\
\hline 4 & 444 & 22 & 1,771 & 1.10 & $0.59,2.06$ & 1.08 & $0.58,2.03$ \\
\hline 5 (high) & 578 & 23 & 1,766 & 1.17 & $0.63,2.17$ & 1.17 & $0.63,2.17$ \\
\hline$p$-trend & & & & 0.81 & & 0.84 & \\
\hline \multicolumn{8}{|l|}{ Total vegetables } \\
\hline 1 (low) $\ddagger$ & 107 & 16 & 1,778 & 1.00 & & 1.00 & \\
\hline 2 & 147 & 24 & 1,706 & 1.59 & $0.83,3.05$ & 1.56 & $0.81,2.99$ \\
\hline 3 & 181 & 22 & 1,837 & 1.37 & $0.70,2.65$ & 1.35 & $0.69,2.61$ \\
\hline 4 & 220 & 25 & 1,759 & 1.64 & $0.86,3.14$ & 1.60 & $0.84,3.06$ \\
\hline 5 (high) & 293 & 28 & 1,735 & 1.85 & $0.98,3.49$ & 1.78 & $0.94,3.38$ \\
\hline p-trend & & & & 0.07 & & 0.09 & \\
\hline \multicolumn{8}{|l|}{ Total fruit } \\
\hline $1($ low $) \ddagger$ & 65 & 16 & 1,324 & 1.00 & & 1.00 & \\
\hline 2 & 124 & 21 & 1,784 & 0.96 & & 0.95 & $0.48,1.87$ \\
\hline 3 & 177 & 29 & 1,827 & 1.31 & $\begin{array}{l}0.49,1.88 \\
0.70 ? 47\end{array}$ & 1.31 & $0.70,2.48$ \\
\hline 4 & 237 & 33 & 2,030 & 1.29 & $\begin{array}{l}0.70,2.41 \\
070 ? 41\end{array}$ & 1.30 & $0.69,2.41$ \\
\hline 5 (high) & 343 & 20 & 2,413 & 0.67 & $\begin{array}{l}0.10,2.41 \\
0.34,1.31\end{array}$ & 0.67 & $0.34,1.33$ \\
\hline$p$-trend & & & & 0.41 & $0.34,1.31$ & 0.44 & \\
\hline
\end{tabular}

* Adjusted for age, family history of colorectal cancer, and category of aicohol intake.

$+\mathrm{RR}$, rate ratio; $\mathrm{Cl}$, confidence interval.

$\ddagger$ Reference category.

etable/fruit consumption on colorectal cancer, there is no doubt about the overall conclusion that negative associations have been observed in most case-control studies.

Comparison of the present data with results from other cohort studies is complicated by the fact that different stud- ies use different endpoints (e.g., colon cancer, rectal cancer, colorectal cancer, or adenomas of the colon or rectum) or sex. groups, and some present results from pooled analyses. In addition, only a few studies have conducted analyses using more than one variable to reflect vegetable or fruit intake. 
TABLE 5. Rate ratios* for colon and rectal cancer according to consumption of specific groups of vegetables and fruits in men and women, Netherlands Cohort Study, 1986-1992

\begin{tabular}{|c|c|c|c|c|c|c|c|c|c|c|}
\hline \multirow{3}{*}{$\begin{array}{l}\text { Quintile or } \\
\text { category of } \\
\text { consumption }\end{array}$} & \multicolumn{5}{|c|}{ Men } & \multicolumn{5}{|c|}{ Women } \\
\hline & \multirow{2}{*}{$\begin{array}{l}\text { Median } \\
\text { Intake } \\
\text { (g/day) }\end{array}$} & \multicolumn{2}{|c|}{ Colon cancer } & \multicolumn{2}{|c|}{ Rectal cancer } & \multirow{2}{*}{$\begin{array}{l}\text { Median } \\
\text { intake } \\
\text { (g/day) }\end{array}$} & \multicolumn{2}{|c|}{ Colon cancer } & \multicolumn{2}{|c|}{ Rectal cancer } \\
\hline & & RRt & $95 \% \mathrm{Clt}$ & RR & $95 \% \mathrm{Cl}$ & & RR & $95 \% \mathrm{Cl}$ & PR & $95 \% \mathrm{Cl}$ \\
\hline \multicolumn{11}{|c|}{ Cooked vegetables } \\
\hline 1 (low) $\ddagger$ & 79 & 1.00 & & 1.00 & & 80 & 1.00 & & 1.00 & \\
\hline 2 & 115 & 0.94 & $0.64,1.39$ & 0.89 & $0.56,1.41$ & 115 & 0.66 & $0.43,1.02$ & 1.08 & $0.58,2.00$ \\
\hline 3 & 143 & 0.85 & $0.57,1.26$ & 0.76 & $0.47,1.22$ & 142 & 0.96 & $0.65,1.43$ & 0.70 & $0.35,1.38$ \\
\hline 4 & 175 & 0.92 & $0.62,1.36$ & 0.77 & $0.48,1.24$ & 174 & 0.87 & $0.58,1.31$ & 1.38 & $0.77,2.48$ \\
\hline 5 (high) & 234 & 0.94 & $0.64,1.39$ & 0.96 & $0.61,1.51$ & 227 & 0.75 & $0.49,1.14$ & 1.34 & $0.74,2.42$ \\
\hline p-trend & & 0.72 & & 0.67 & & & 0.43 & & 0.18 & \\
\hline \multicolumn{11}{|l|}{ Raw vegetables } \\
\hline $1(l o w) \ddagger$ & 7 & 1.00 & & 1.00 & & 10 & 1.00 & & 1.00 & \\
\hline 2 & 19 & 0.56 & $0.37,0.84$ & 0.71 & $0.43,1.17$ & 25 & 0.95 & $0.63,1.42$ & 0.82 & $0.42,1.56$ \\
\hline 3 & 30 & 0.88 & $0.61,1.27$ & 1.00 & $0.63,1.56$ & 37 & 0.92 & $0.60,1.39$ & 1.40 & $0.78,2.51$ \\
\hline 4 & 44 & 0.77 & $0.53,1.13$ & 0.93 & $0.59,1.47$ & 50 & 0.68 & $0.43,1.06$ & 0.92 & $0.48,1.75$ \\
\hline 5 (high) & 73 & 0.79 & $0.54,1.16$ & 0.93 & $0.58,1.47$ & 76 & 1.02 & $0.67,1.54$ & 1.24 & $0.67,2.26$ \\
\hline$p$-trend & & 0.47 & & 0.91 & & & 0.53 & & 0.42 & \\
\hline \multicolumn{11}{|l|}{ Legumes } \\
\hline 1 (low) $\ddagger$ & 11 & 1.00 & & 1.00 & & 10 & 1.00 & & 1.00 & \\
\hline 2 & 22 & 0.95 & $0.65,1.40$ & 0.89 & $0.56,1.42$ & 18 & 0.65 & $0.42,1.00$ & 1.07 & $0.57,2.00$ \\
\hline 3 & 30 & 0.83 & $0.55,1.25$ & 0.90 & $0.56,1.46$ & 26 & 1.02 & $0.68,1.51$ & 1.40 & $0.77,2.57$ \\
\hline 4 & 40 & 1.02 & $0.69,1.51$ & 1.07 & $0.67,1.69$ & 37 & 0.86 & $0.57,1.29$ & 1.44 & $0.79,2.62$ \\
\hline 5 (high) & 62 & 1.13 & $0.77,1.64$ & 0.92 & $0.58,1.47$ & 58 & 0.79 & $0.52,1.20$ & 1.01 & $0.53,1.94$ \\
\hline p-trend & & 0.41 & & 0.97 & & & 0.58 & & 0.59 & \\
\hline \multicolumn{11}{|c|}{ Brassica vegetables } \\
\hline $1(\mathrm{low}) \ddagger$ & 11 & 1.00 & & 1.00 & & 11 & 1.00 & & 1.00 & \\
\hline $2^{(18)}$ & 21 & 1.00 & $0.69,1.46$ & 0.73 & $0.45,1.18$ & 20 & 0.60 & $0.40,0.89$ & 0.83 & $0.44,1.57$ \\
\hline 3 & 29 & 0.82 & $0.56,1.22$ & 0.79 & $0.49,1.26$ & 28 & 0.85 & $0.58,1.25$ & 1.28 & $0.70,2.33$ \\
\hline 4 & 40 & 0.91 & $0.62,1.32$ & 0.95 & $0.61,1.48$ & 38 & 0.66 & $0.44,0.99$ & 1.01 & $0.53,1.90$ \\
\hline 5 (high) & 58 & 0.76 & $0.51,1.13$ & 0.88 & $0.56,1.39$ & 58 & 0.51 & $0.33,0.80$ & 1.66 & $0.94,2.94$ \\
\hline$p$-trend & & 0.11 & & 0.94 & & & 0.004 & & 0.05 & \\
\hline \multicolumn{11}{|c|}{$\begin{array}{c}\text { Leafy vegetables, } \\
\text { cooked }\end{array}$} \\
\hline 1 (low) $\ddagger$ & 4 & 1.00 & & 1.00 & & 4 & 1.00 & & 1.00 & \\
\hline 2 & 12 & 1.05 & $0.72,1.52$ & 0.86 & $0.53,1.39$ & 12 & 0.99 & $0.67,1.48$ & 1.00 & $0.55,1.84$ \\
\hline 3 & 19 & 0.79 & $0.53,1.18$ & 1.19 & $0.76,1.88$ & 19 & 0.94 & $0.62,1.41$ & 1.30 & $0.73,2.32$ \\
\hline 4 & 27 & 0.84 & $0.57,1.25$ & 1.00 & $0.62,1.60$ & 27 & 1.03 & $0.69,1.53$ & 1.02 & $0.55,1.88$ \\
\hline 5 (high) & 41 & 0.75 & $0.50,1.13$ & 0.88 & $0.54,1.44$ & 41 & 0.62 & $0.40,0.96$ & 1.16 & $0.65,2.07$ \\
\hline$p$-trend & & 0.05 & & 0.86 & & & 0.06 & & 0.61 & \\
\hline \multicolumn{11}{|c|}{$\begin{array}{l}\text { Leafy vegetables, } \\
\text { raw }\end{array}$} \\
\hline Lowł & 3 & 1.00 & & 1.00 & & 3 & 1.00 & & 1.00 & \\
\hline Medium & 8 & 0.97 & $0.71,1.31$ & 1.13 & $0.79,1.62$ & 8 & 0.82 & $0.59,1.14$ & 0.82 & $0.51,1.32$ \\
\hline High & 18 & 1.02 & $0.75,1.38$ & 0.95 & $0.66,1.39$ & 18 & 0.98 & $0.71,1.35$ & 1.11 & $0.70,1.75$ \\
\hline$p$-trend & & 0.92 & & 0.83 & & & 0.85 & & 0.64 & \\
\hline \multicolumn{11}{|l|}{ Citrus fruit } \\
\hline 1 (low) $\ddagger$ & 0 & 1.00 & & 1.00 & & 8 & 1.00 & & 1.00 & \\
\hline 2 & 17 & 0.95 & $0.64,1.41$ & 0.74 & $0.47,1.18$ & 38 & 0.95 & $0.62,1.45$ & 0.96 & $0.51,1.79$ \\
\hline 3 & 41 & 0.95 & $0.64,1.40$ & 1.00 & $0.65,1.54$ & 79 & 1.22 & $0.82,1.81$ & 1.08 & $0.59,1.97$ \\
\hline 4 & 83 & 1.08 & $0.74,1.58$ & 0.81 & $0.52,1.27$ & 111 & 0.94 & $0.62,1.45$ & 1.27 & $0.70,2.30$ \\
\hline 5 (high) & 167 & 1.09 & $0.75,1.59$ & 0.77 & $0.49,1.20$ & 187 & 1.00 & $0.66,1.52$ & 1.16 & $0.63,2.12$ \\
\hline$p$-trend & & 0.44 & & 0.33 & & & 0.99 & & 0.38 & \\
\hline
\end{tabular}

* The model included age, family history of colorectal cancer, and category of alcohol intake.

$\uparrow \mathrm{RR}$, rate ratio; $\mathrm{Cl}$, confidence Interval.

¥ Reference category.

In the present study, negative associations with vegetable and fruit consumption were more pronounced for women than for men. Similar differences have been observed in all other cohort studies presenting data on both men and women $(5,11,12)$. It has been suggested that this could be attributed to greater accuracy of female food intake data, since traditionally women have been responsible for food preparation (12). Our questionnaire was validated against dietary records, and correlation coefficients for vegetables and fruits did not differ between the sexes (23).

In our study, more detailed analyses of groups of vegetables and of specific vegetables and fruits did show negative associations with Brassica vegetables and cooked leafy vegetables for colon cancer in both men and women. Brassica vegetables are known to have cancer-preventive effects (27). It has been suggested that the protective effect may be 
TABLE 6. Rate ratios for colon and rectal cancer according to consumption of individual vegetables and fruits (continuous variables), per 25-g/day increment, in men and women: Netherlands Cohort Study, 1986-1992*

\begin{tabular}{|c|c|c|c|c|c|c|c|c|c|}
\hline & \multirow{3}{*}{$\begin{array}{c}\text { Mean } \\
\text { intake } \\
\text { in } \\
\text { subcohort } \\
\text { (g/day) }\end{array}$} & \multicolumn{4}{|c|}{ Colon cancer } & \multicolumn{4}{|c|}{ Rectal cancer } \\
\hline & & \multicolumn{2}{|c|}{ Men } & \multicolumn{2}{|c|}{ Women } & \multicolumn{2}{|c|}{ Men } & \multicolumn{2}{|c|}{ Women } \\
\hline & & $\begin{array}{l}\text { Rate } \\
\text { ratiof }\end{array}$ & $\begin{array}{c}\text { Adjusted } \\
\text { rate } \\
\text { ratio } \neq\end{array}$ & $\begin{array}{l}\text { Rate } \\
\text { ratiof }\end{array}$ & $\begin{array}{c}\text { Adjusted } \\
\text { rate } \\
\text { ratio } \neq\end{array}$ & $\begin{array}{l}\text { Rate } \\
\text { ratiot }\end{array}$ & $\begin{array}{c}\text { Adjusted } \\
\text { rate } \\
\text { ratioł }\end{array}$ & $\begin{array}{l}\text { Rate } \\
\text { ratio† }\end{array}$ & $\begin{array}{c}\text { Adjusted } \\
\text { rate } \\
\text { ratio } \neq\end{array}$ \\
\hline Total vegetables & 189.7 & 0.98 & & 0.97 & & 0.99 & & 1.05 & \\
\hline Cooked vegetables & 150.8 & 1.00 & & 0.96 & & 0.98 & & 1.05 & \\
\hline Brussels sprouts & 7.7 & 0.87 & 0.94 & 0.61 & 0.89 & 0.89 & 0.99 & 0.89 & 0.53 \\
\hline Cauliflower & 14.2 & 0.90 & 0.97 & 0.62 & 0.69 & 0.92 & 0.91 & 1.62 & 1.73 \\
\hline Cabbage & 7.0 & 0.74 & 0.76 & 0.69 & 0.76 & 1.00 & 1.03 & 1.14 & 1.10 \\
\hline Spinach & 9.5 & 0.96 & 1.09 & 0.63 & 0.76 & 1.02 & 1.04 & 1.31 & 1.18 \\
\hline Endive, cooked & 11.9 & 0.72 & 0.68 & 0.87 & 1.03 & 0.97 & 0.99 & 1.15 & 0.94 \\
\hline Beetroot & 7.9 & 0.94 & 1.02 & 0.96 & 1.16 & 1.01 & 1.06 & 1.28 & 1.17 \\
\hline String beans & 20.0 & 1.08 & 1.18 & 0.79 & 0.85 & 0.96 & 0.98 & 0.88 & 0.67 \\
\hline Broad beans & 4.5 & 1.02 & 1.02 & 0.89 & 1,22 & 0.67 & 0.64 & 1.89 & 1.98 \\
\hline Kale & 3.3 & 0.71 & 0.76 & 0.39 & 0.56 & 1.60 & 2.02 & 0.91 & 0.71 \\
\hline Carrots, cooked & 8.9 & 0.99 & 1.07 & 1.05 & 1.28 & 0.97 & 0.96 & 1.20 & 1.08 \\
\hline Sweet peppers & 2.9 & 1.48 & 1.69 & 1.15 & 1.26 & 1.03 & 1.03 & 2.02 & 1.83 \\
\hline Saverkraut & 5.8 & 0.89 & 1.15 & 0.80 & 1.27 & 0.97 & 0.92 & 1.31 & 1.24 \\
\hline Rhubarb & 2.3 & 1.32 & 1.37 & 0.89 & 0.90 & 0.78 & 0.76 & 0.56 & 0.57 \\
\hline Mushrooms & 3.5 & 1.13 & 0.97 & 0.94 & 1.02 & 0.99 & 1.02 & 2.39 & 1.70 \\
\hline Gherkins & 1.9 & 0.65 & 0.66 & 0.74 & 0.77 & 0.95 & 0.91 & 0.69 & 0.58 \\
\hline Raw vegetables & 38.9 & 0.91 & & 0.96 & & 1.03 & & 1.11 & \\
\hline Endive & 2.4 & 0.50 & 0.49 & 0.96 & 2.00 & 0.54 & 0.51 & 2.16 & 2.00 \\
\hline Carrots & 2.8 & 0.75 & 0.78 & 0.89 & 1.07 & 1.02 & 1.05 & 1.20 & 1.07 \\
\hline Lettuce & 7.6 & 1.18 & 1.43 & 0.88 & 0.80 & 0.93 & 0.95 & 0.99 & 0.80 \\
\hline Tomatoes & 21.5 & 0.93 & 0.93 & 0.97 & 1.18 & 1.10 & 1.11 & 1.20 & 1.18 \\
\hline Total fruit & 175.7 & 1.00 & & 0.98 & & 1.00 & & 1.00 & \\
\hline Citrus fruit & 76.8 & 1.01 & & 1.01 & & 0.98 & & 1.01 & \\
\hline Mandarins & 4.7 & 0.68 & 0.69 & 1.18 & 1.26 & 0.86 & 0.96 & 1.40 & 1.61 \\
\hline Oranges/fresh orange juice & 48.4 & 1.00 & 1.00 & 1.01 & 1.01 & 1.02 & 1.02 & 0.98 & 0.98 \\
\hline Grapefruits/fresh grapefruit juice & 9.1 & 1.07 & 1.07 & 1.03 & 1.04 & 0.98 & 0.99 & 1.03 & 1.05 \\
\hline Grapes & 4.5 & 0.97 & 1.08 & 1.02 & 1.08 & 0.83 & 0.92 & 0.62 & 0.58 \\
\hline Bananas & 12.9 & 0.98 & 0.99 & 0.88 & 0.88 & 0.88 & 0.90 & 0.77 & 0.77 \\
\hline Apples, pears & 76.0 & 1.01 & 1.01 & 0.97 & 0.97 & 1.01 & 1.01 & 0.97 & 0.97 \\
\hline Strawberries & 7.5 & 0.70 & 0.71 & 0.70 & 0.68 & 0.61 & 0.64 & 0.99 & 1.14 \\
\hline Orange/grapefruit juice & 14.5 & 1.00 & 1.00 & 0.99 & 0.99 & 0.86 & 0.87 & 1.05 & 1.07 \\
\hline Other fruit juices & 10.4 & 1.04 & 1.04 & 0.99 & 1.00 & 0.91 & 0.93 & 0.87 & 0.87 \\
\hline
\end{tabular}

* Results are presented with and without adjustment for consumption of other cooked or raw vegetables, or other fruits.

$\dagger$ Adjusted for age, alcohol intake, and family history of colorectal cancer.

$\ddagger$ Additionally adjusted by simultaneous inclusion of items in the cooked vegetable group, the raw vegetable group, and the fruit group, respectively.

partly due to these vegetables' relatively high content of glucosinolates, of which certain hydrolysis products have shown anticarcinogenic properties (28). However, other cohort studies that have presented data on Brassica vegetables have found no association or a positive association. No association was found for colon cancer in the Iowa Women's Health Study (13) or for adenoma in the Health Professionals Follow-up Study (16); a positive association with colorectal cancer was found among male smokers in the Alpha-Tocopherol, Beta-Carotene Cancer Prevention Study (18).

For rectal cancer, inverse associations with vegetable and/or fruit consumption were not found in either sex. Associations even tended to be positive for total vegetable consumption and consumption of Brassica vegetables in women.

Separate analyses on subsites of the colon showed stronger inverse relations of vegetable consumption with cancer of the distal colon than with cancer of the proximal colon. For women, similar results on subsites were found in the Iowa Women's Health Study (13). The fiber in vegetables and fruits might dilute concentrations of carcinogens by increasing fecal bulk in the distal part of the colon. In the other prospective study that presented data on colon subsites, the Nurses' Health Study, investigators reported no effect of total dietary fiber (the only variable included in separate analyses) on either subsite (10). 
TABLE 7. Rate ratlos for colon cancer according to quintlles of vegetable and/or fruit consumption in men and women, by subsite: Netherlands Cohort Study, 1986-1992*

\begin{tabular}{|c|c|c|c|c|c|c|c|c|}
\hline \multirow{3}{*}{$\begin{array}{c}\text { Quintile } \\
\text { of } \\
\text { consumption }\end{array}$} & \multicolumn{4}{|c|}{ Men } & \multicolumn{4}{|c|}{ Women } \\
\hline & \multicolumn{2}{|c|}{ Proximal colon } & \multicolumn{2}{|c|}{ Distal colon } & \multicolumn{2}{|c|}{ Proximal colon } & \multicolumn{2}{|c|}{ Distal colon } \\
\hline & RRt & $95 \% \mathrm{Clt}$ & RR & $95 \% \mathrm{Cl}$ & RR & $95 \% \mathrm{Cl}$ & RR & $95 \% \mathrm{Cl}$ \\
\hline & \multicolumn{2}{|c|}{$(n=148)$} & \multicolumn{2}{|c|}{$(n=153)$} & \multicolumn{2}{|c|}{$(n=138)$} & \multicolumn{2}{|c|}{$(n=116)$} \\
\hline \multicolumn{9}{|c|}{ Total vegetables and fruits } \\
\hline 1 (low) $\ddagger$ & 1.00 & & 1.00 & & 1.00 & & 1.00 & \\
\hline 2 & 0.93 & $0.53,1.63$ & 0.73 & $0.42,1.30$ & 0.61 & $0.34,1.10$ & 0.63 & $0.36,1.11$ \\
\hline 3 & 1.01 & $0.58,1.75$ & 1.05 & $0.62,1.76$ & 0.82 & $0.48,1.41$ & 0.71 & $0.42,1.22$ \\
\hline 4 & 1.07 & $0.62,1.84$ & 1.00 & $0.59,1.71$ & 0.91 & $0.54,1.54$ & 0.57 & $0.32,1.01$ \\
\hline 5 (high) & 0.89 & $0.51,1.56$ & 1.04 & $0.62,1.75$ & 0.89 & $0.52,1.51$ & 0.44 & $0.23,0.82$ \\
\hline$p$-trend & 0.89 & & 0.53 & & 0.90 & & 0.01 & \\
\hline \multicolumn{9}{|l|}{ Total vegetables } \\
\hline $1($ low) $\ddagger$ & 1.00 & & 1.00 & & 1.00 & & 1.00 & \\
\hline 2 & 1.01 & $0.58,1.77$ & 0.89 & $0.53,1.49$ & 0.76 & $0.42,1.36$ & 0.75 & $0.43,1.33$ \\
\hline 3 & 1.11 & $0.64,1.92$ & 0.82 & $0.48,1.38$ & 0.96 & $0.56,1.65$ & 0.95 & $0.56,1.61$ \\
\hline 4 & 1.13 & $0.65,1.97$ & 0.88 & $0.53,1.49$ & 1.11 & $0.65,1.89$ & 0.43 & $0.22,0.83$ \\
\hline 5 (high) & 1.03 & $0.59,1.81$ & 0.76 & $0.27,1.30$ & 0.99 & $0.57,1.72$ & 0.64 & $0.36,1.17$ \\
\hline$p$-trend & 0.78 & & 0.33 & & 0.58 & & 0.04 & \\
\hline \multicolumn{9}{|l|}{ Brassica vegetables } \\
\hline $1($ low) $\ddagger$ & 1.00 & & 1.00 & & 1.00 & & 1.00 & \\
\hline 2 & 1.26 & $0.73,2.17$ & 0.96 & $0.59,1.56$ & 0.70 & $0.42,1.17$ & 0.56 & $0.32,1.00$ \\
\hline 3 & 1.02 & $0.57,1.81$ & 0.79 & $0.47,1.32$ & 0.76 & $0.44,1.29$ & 1.06 & $0.64,1.77$ \\
\hline 4 & 1.38 & $0.82,2.32$ & 0.57 & $0.33,0.99$ & 0.82 & $0.49,1.39$ & 0.53 & $0.28,0.98$ \\
\hline 5 (high) & 0.93 & $0.52,1.66$ & 0.68 & $0.41,1.15$ & 0.57 & $0.32,1.02$ & 0.47 & $0.25,0.89$ \\
\hline \multirow[t]{2}{*}{$p$-trend } & 0.96 & & 0.02 & & 0.12 & & 0.02 & \\
\hline & \multicolumn{2}{|c|}{$(n=159)$} & \multicolumn{2}{|c|}{$(n=160)$} & \multicolumn{2}{|c|}{$(n=144)$} & \multicolumn{2}{|c|}{$(n=122)$} \\
\hline \multicolumn{9}{|l|}{ Total fruit } \\
\hline $1($ low $) \ddagger$ & 1.00 & & 1.00 & & 1.00 & & 1.00 & \\
\hline 2 & 1.44 & $0.86,2.43$ & 1.28 & $0.74,2.21$ & 0.88 & $0.50,1.54$ & 1.07 & $0.57,2.00$ \\
\hline 3 & 0.78 & $0.43,1.41$ & 1.04 & $0.59,1.83$ & 0.65 & $0.36,1.19$ & 1.01 & $0.54,1.90$ \\
\hline 4 & 1.21 & $0.71,2.05$ & 1.38 & $0.81,2.37$ & 0.77 & $0.44,1.35$ & 1.04 & $0.57,1.92$ \\
\hline 5 (high) & 1.20 & $0.71,2.05$ & 1.49 & $0.88,2.54$ & 0.81 & $0.47,1.39$ & 0.59 & $0.30,1.13$ \\
\hline$\rho$-trend & 0.76 & & 0.11 & & 0.43 & & 0.09 & \\
\hline
\end{tabular}

* The model included age, family history of colorectal cancer, and category of alcohol intake.

$\uparrow \mathrm{RR}$, rate ratio; $\mathrm{Cl}$, confidence interval.

‡ Reference category.

Alcohol intake and family history of colorectal cancer were included in the analyses, because these variables showed an effect on colon and/or rectal cancer risk. Subjects in the highest category of alcohol intake $(\geq 30$ $\mathrm{g}$ /day) had an increased risk of colorectal cancer compared with abstainers (rate ratios were 2.2 for rectal cancer in both sexes, 1.5 for colon cancer in men, and 1.8 for colon cancer in women). Having a family history of colorectal cancer doubled the risks for colon and rectal cancer in men and for colon cancer in women, whereas it did not seem to be associated with rectal cancer risk in women. Rate ratios for age were 1.09 for colon cancer and 1.07 for rectal cancer per 1-year increment. Adjustment for pack-years of cigarettes smoked, leisure time physical activity, body mass index, and total energy consumption did not influence estimated rate ratios and thus were not included in the model.
Surprisingly, we found that increased alcohol intake was related to higher vegetable consumption among both men and women in the subcohort. This was not a direct effect of socioeconomic status, because in stratified analyses the relation was found within each socioeconomic subgroup (data not shown). Additional analyses revealed that this relation resulted from a larger reported serving size of vegetables, not a higher frequency of consumption, among subjects with a higher alcohol intake. In addition, the reported serving size of meat appeared to be higher among these subjects. However, adjustment for alcohol intake did not change rate ratio estimates importantly.

Generally, information bias-i.e., changes in the reported dietary habits of cases due to their disease - is largely avoided in prospective studies, since dietary habits are reported before the disease is diagnosed. However, in the Netherlands Cohort Study, vegetable and fruit consumption 
might have been influenced by the presence of latent colorectal cancer. We think this is unlikely, because neither vegetable consumption nor fruit consumption differed between colon and rectal cancer cases detected during the first 2 years of follow-up and cases detected in later years. Actually, repeating the analyses after exclusion of cases detected during the first 2 years of follow-up did not affect the results importantly.

Other circumstances might have been responsible for obscuring associations between vegetable consumption and colorectal cancer risk. However, with 514 male and 396 female colorectal cancer cases, the power of this study should have been sufficiently large to detect important associations. In addition, the possibility of selection bias due to exposurerelated loss to follow-up can be excluded, since the completeness of follow-up for cancer incidence was estimated at more than 96 percent and no subcohort members were lost to follow-up. Another reason for our not finding a clear postulated association between vegetable consumption and colorectal cancer incidence might be that the dietary habits assessed by our questionnaire do not sufficiently reflect dietary intakes in previous decades, the time span needed for development of colorectal cancer. To avoid this problem, researchers in the Nurses' Health Study (10) and the Health Professionals Follow-up Study $(14,16)$ focused on colorectal adenomatous polyps; as precursors of colon cancer, such polyps antedate the clinical diagnosis of colorectal cancer by an average of 10 years (29). Initially, dietary fiber from all sources (vegetables, fruits, and grains) was significantly associated with a lower risk of colorectal adenoma in men (14); but with longer follow-up and multivariate analyses, only fiber from fruit, not that from vegetables or cereals, appeared to be protective (16). However, incident adenomatous polyps (those appearing after a "clean" endoscopy prior to the start of the study) did show inverse associations for fiber from fruit (but not fiber from vegetables). Fruits and folate-rich vegetables showed significant inverse associations with adenomatous polyps of the distal colon (16). No association of fiber from vegetables or fruit with distal colorectal adenomas was found for women (10).

Could the assessment of vegetable or fruit consumption itself have biased the results obtained? To minimize the amount of uninformative data, in addition to the general dietary exclusion criteria, we excluded subjects who appeared not to have understood how to fill in the questions on vegetable consumption, which appeared in the first part of the food frequency questionnaire; those subjects were defined by an extreme score on the vegetable error index. Vegetable intakes are generally considered difficult to assess with food frequency questionnaires (as well as with other methods of dietary assessment), particularly if portion sizes have to be estimated. In our validation study, the correlation coefficient for total vegetable consumption was $0.4(21)$; this is quite low but is comparable to the figures reported for many other prospective studies, including the Dutch part of the EPIC Study (European Prospective Investigation into Cancer and Nutrition) (30) and the study of Japanese-American men in Hawaii (31). One reason for the low correlation may be a relative lack of true contrast in frequencies of total vegetable consumption among our subjects, because the Dutch are accustomed to eating only one hot meal per day, almost always including vegetables. Coefficients of variation for total vegetable consumption are approximately 40 percent for both men and women. A consequence of a relatively large measurement error, resulting in an attenuation of the estimated rate ratio, is underestimation of the inverse association between total vegetable consumption and colorectal cancer. Because of individual preferences, contrast in consumption frequencies is much higher for specific vegetables (coefficient of variation -100 percent). Therefore, a smaller error is expected for the assessment of specific vegetables, and inverse associations with colon and/or rectal cancer will be less likely to be obscured. It was not possible to assess validity for specific vegetables in our validation study, since 9 days of dietary records are not sufficient for estimating the consumption frequency of specific vegetables. For fruit consumption, more contrast is observed than for vegetables (coefficient of variation $=73$ percent for men and 61 percent for women), and portion sizes are easier to estimate, reducing the measurement error.

Another explanation that must be considered in interpreting these results is that unmeasured or unknown factors may have caused some confounding. However, it is unlikely that such factors had a great impact on the association between vegetable or fruit consumption and colon or rectal cancer incidence. Because of multiple comparisons, chance might have played a role in our findings, particularly in the analyses of specific vegetables.

The present analyses confirm that, especially for men, the evidence for a protective effect of vegetables on risks of colon and rectal cancer is less strong in cohort studies than in case-control studies. From these data, it cannot be concluded in general that increased vegetable or fruit consumption will lead to a considerable decrease in colorectal cancer risk, although Brassica vegetables were exceptional in showing rather strong negative associations with colon cancer in both sexes. However, with regard to rectal cancer, Brassica vegetables appear to enhance risk in women. No conclusion can be drawn about the protective effect of increasing consumption of vegetables among subjects with very low vegetable or fruit consumption, since these people were not well represented in the cohort. Likewise, we cannot exclude the possibility that vegetables and fruits play a more important role among subjects with certain dietary habits, such as very high meat consumption. Further analyses will be necessary to test these hypotheses.

\section{ACKNOWLEDGMENTS}

This study was financially supported by the Dutch Cancer Society, the Dutch Product Board for Horticulture, and Unilever Research Laboratories (Vlaardingen, The Netherlands).

The authors gratefully acknowledge the regional cancer registries, the Dutch Network and National Database for Pathology (PALGA), and the National Health Care Information Center for providing incidence data. 


\section{REFERENCES}

1. Trock B, Lanza E, Greenwald P. Dietary fiber, vegetables, and colon cancer: critical review and meta-analyses of the epidemiological evidence. J Natl Cancer Inst 1990;82:650-61.

2. Steinmetz KA, Potter JD. Vegetables, fruit, and cancer. I. Epidemiology. Cancer Causes Control 1991;2:325-57.

3. Block G, Patterson B, Subar A. Fruit, vegetables, and cancer prevention: a review of the epidemiological evidence. Nutr Cancer 1992;18:1-29.

4. Steinmetz KA, Potter JD. Vegetables, fruit, and cancer prevention: a review. J Am Diet Assoc 1996;96:1027-39.

5. Philips R, Snowdon DA. Dietary relationships with fatal colorectal cancer among Seventh-Day Adventists. J Natl Cancer Inst 1985;74:307-17.

6. Singh PN, Fraser GE. Dietary risk factors for colon cancer in a low-risk population. Am J Epidemiol 1998;148:761-74.

7. Heilbrun LK, Nomura A, Hankin JH, et al. Diet and colorectal cancer with special reference to fiber intake. Int J Cancer 1989; $44: 1-6$.

8. Key TJ, Thorogood M, Appleby PN, et al. Dietary habits and mortality in 11,000 vegetarians and health conscious people: results of a 17 year follow up. BMJ 1996;313:775-9.

9. Willett WC, Stampfer M, Colditz GA, et al. Relation of meat, fat and fiber intake to the risk of colon cancer in a prospective study among women. N Engl J Med 1990;323:1664-72.

10. Fuchs CS, Giovannucci EL, Colditz GA, et al. Dietary fiber and the risk of colorectal cancer and adenoma in women. $\mathrm{N}$ Engl J Med 1999;340:169-76.

11. Thun MJ, Calle EE, Namboodiri MM, et al. Risk factors for fatal colon cancer in a prospective study. J Natl Cancer Inst 1992;84:1491-500.

12. Shibata A, Paganini-Hill A, Ross RK, et al. Intake of vegetables, fruits, beta-carotene, vitamin $C$ and vitamin supplements and cancer incidence among the elderly: a prospective study. Br J Cancer 1992;66:673-9.

13. Steinmetz KA, Kushi LH, Bostick RM, et al. Vegetables, fruit, and colon cancer in the Iowa Women's Health Study. Am J Epidemiol 1994;139:1-15.

14. Giovannucci E, Stampfer M, Colditz GA, et al. Relation of diet to risk of colorectal adenoma in men. J Natl Cancer Inst 1992; 84:91-8.

15. Giovannucci E, Rimm EB, Stampfer MJ, et al. Intake of fat, meat, and fiber in relation to risk of colon cancer in men. Cancer Res 1994;54:2390-7.

16. Platz EA, Giovannucci E, Rimm EB, et al. Dietary fiber and colorectal adenomas in men. Cancer Epidemiol Biomark Prev $1997 ; 6: 661-70$.
17. Kato I, Akhmedkhanov A, Koenig K, et al. Prospective study of diet and female colorectal cancer: The New York University Women's Health Study. Nutr Cancer 1997;28:276-81.

18. Pietinen $P$, Malila $N$, Virtanen $M$, et al. Diet and risk of colorectal cancer in a cohort of Finnish men. Cancer Causes Control 1999;10:387-96.

19. Dorant E, van den Brandt PA, Goldbohm RA. A prospective cohort study on the relationship between onion and leek consumption, garlic supplement use and the risk of colorectal carcinoma in the Netherlands. Carcinogenesis 1996;17:477-84.

20. van den Brandt PA, Goldbohm RA, van 't Veer P, et al. A largescale prospective cohort study on diet and cancer in the Netherlands. J Clin Epidemiol 1990;43:285-95.

21. van den Brandt PA, Schouten LJ, Goldbohm RA, et al. Development of a record linkage protocol for use in the Dutch cancer registry for epidemiological research. Int J Epidemiol 1990;19:553-8.

22. Ministerie van Welzijn, Volksgezondheid en Cultuur en Ministerie van Landbouw en Visserij. Wat eet Nederland: resultaten van de voedselconsumptiepeiling 1987-1988. (In Dutch). Rijswijk, The Netherlands: Distributiecentrum DOP, 1988.

23. Goldbohm RA, van den Brandt PA, Brants HA, et al. Validation of a dietary questionnaire used in a large-scale prospective cohort study on diet and cancer. Eur J Clin Nutr 1994;48:253-65.

24. Self SG, Prentice RL. Asymptotic distribution theory and efficiency results for case-cohort studies. Ann Stat 1988;16: 64-81.

25. Baker RJ. GLIM 3.77 reference manual. Oxford, United Kingdom: Numerical Algorithms Group, 1985.

26. Volovics A, van den Brandt PA. Methods for the analyses of case-cohort studies. Biom J 1997;39:195-214.

27. Verhoeven DT, Goldbohm RA, van Poppel G, et al. Epidemiological studies on brassica vegetables and cancer risk. Cancer Epidemiol Biomark Prev 1996;5:733-48.

28. Verhoeven DT, Verhagen $H$, Goldbohm RA, et al. A review of mechanisms underlying anticarcinogenicity by brassica vegetables. Chem Biol Interact 1997;103:79-129

29. Lev R. Adenomatous polyps of the colon. New York, NY: Springer-Verlag New York, 1990.

30. Ocké M, Bueno de Mesquita B, Goddijn E, et al. The Dutch EPIC food frequency questionnaire. I. Description of the questionnaire, and relative validity and reproducibility for food groups. Int J Epidemiol 1997;26(suppl):S37-48.

31. Hankin JH, Wilkins LR, Kolonel LN, et al. Validation of a quantitative diet history method in Hawaii. Am J Epidemiol 1991;133:616-28. 